\title{
Imaging of Abnormal Air in the Abdomen and Pelvis
}

\author{
${ }^{1}$ Department of Radiology, University of Arkansas for Medical \\ Sciences, Little Rock, Arkansas, United States \\ 2Department of Radiology, University of Kansas Medical Center, \\ Kansas City, Missouri, United States
}

Shobhit Sharma ${ }^{1}$ Jonathan McDougal ${ }^{2}$ Tarun Pandey ${ }^{1}$ Kedar Jambhekar ${ }^{1}$ Roopa Ram

\begin{abstract}
Address for correspondence Roopa Ram, MD, Department of Radiology, University of Arkansas for Medical Sciences, Slot 556, 4301, West Markham Street, Little Rock, AR 72205, United States (e-mail: rram@uams.edu).
\end{abstract}

J Gastrointestinal Abdominal Radiol ISGAR 2019;2:87-97
Abstract
Keywords
- air
- pneumomediastinum
- pneumoperitoneum
- pneumothorax

The presence of abnormal air collection on an imaging study is quite often the reason as well as the solution to a diagnostic dilemma. The purpose of this review article is to develop an understanding of anatomical localization and determine etiology of abnormal air collections in the abdomen and pelvis. Abnormal air collections are commonly encountered on imaging studies on a daily basis, and this article will help familiarize the interpreting radiologist with the pathophysiology of these collections and help solve various diagnostic challenges and avoid potential pitfalls.

\section{Introduction}

The presence of abnormal air collection on an imaging study is quite often the reason as well as the solution to a diagnostic dilemma. The purpose of this review article is to develop an understanding of anatomical localization and determine etiology of abnormal air collections in the abdominopelvic region. Abnormal air collections are commonly encountered on imaging studies on a daily basis and this case-based approach will help familiarize the interpreting radiologist with the pathophysiology of these collections and help solve various diagnostic challenges and avoid potential pitfalls.

Paranasal sinuses, mastoid antra and middle ear cavities, gastrointestinal, and respiratory tract are the normal aircontaining structures in the body. Presence of abnormal air collections outside these expected locations in the absence of surgical intervention can often be pathological. Patterns of air collection and the proximity to the air-containing viscera where they are located often helps in narrowing down the differential diagnosis. We present a diagnostic review of various causes of abnormal air in the abdomen.

\section{Imaging of Abnormal Air Collections in the Abdomen}

\section{Pneumoperitoneum}

Fascial planes allow movement of air between the various compartments of the thorax, abdomen, and pelvis, thus demonstrating the continuity of these spaces. Mediastinal air can have peritoneal extension across the diaphragm

\section{received}

November 30, 2018

accepted after revision

February 15, 2019

published online

July 19, 2019

by dissecting along the vascular sheaths. ${ }^{1}$ It can extend into the retroperitoneal space via postesophageal areolar tissue or aortic hiatus. ${ }^{2}$ Retroperitoneal air under tension can breach parietal peritoneum and thus can present as intraperitoneal free air. ${ }^{3}$ Similarly, intraperitoneal and retroperitoneal air can extend into the mediastinum. Air can also dissect into the extraperitoneal space from the mediastinum, peritoneal space, retroperitoneal space, or pelvic region. ${ }^{4}$ Thin muscular/vascular septations within the air collection are the key to diagnosing extraperitoneal air (-Figs. 1 and $\mathbf{2}$ ). ${ }^{5}$

The potential causes for pneumoperitoneum include perforated bowel, perforated tumor, ${ }^{6}$ infection, diverticulitis, bowel obstruction, ${ }^{7}$ bowel ischemia, ${ }^{8}$ perforated appendicitis, volvulus, hernia, colonoscopy, esophagogastroduodenoscopy, endoscopic retrograde cholangiopancreatography (ERCP), peritoneal dialysis, ${ }^{9}$ postsurgical, ${ }^{10}$ penetrating trauma, and pneumomediastinal free air extension ( - Table $\mathbf{1}) .^{11}$

\section{Pneumoretroperitoneum}

Pneumoretroperitoneum ( $\boldsymbol{- \text { Fig. }}$ 3) can be caused by a perforated retroperitoneal hollow viscus (duodenum, ascending/descending colon, rectum) ( $\boldsymbol{- \text { Fig. }} \mathbf{3 A}$ and $\mathbf{B}$ ), blunt and penetrating abdominal trauma, foreign body insertion, diverticulitis, ${ }^{12}$ and emphysematous cholecystitis..$^{13}$ It can be secondary to procedures such as ERCP ( $\boldsymbol{- \text { Fig. }}$ 3C) with sphincterotomy, hemorrhoidectomy, ${ }^{14}$ transanal excision of rectal carcinoma, ${ }^{15}$ endoscopy, colonoscopy, or residual air from retroperitoneal surgery, urological/adrenal, and spinal (anterolateral approach) procedures ( - Table 2$).{ }^{16}$

License terms

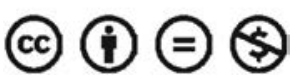



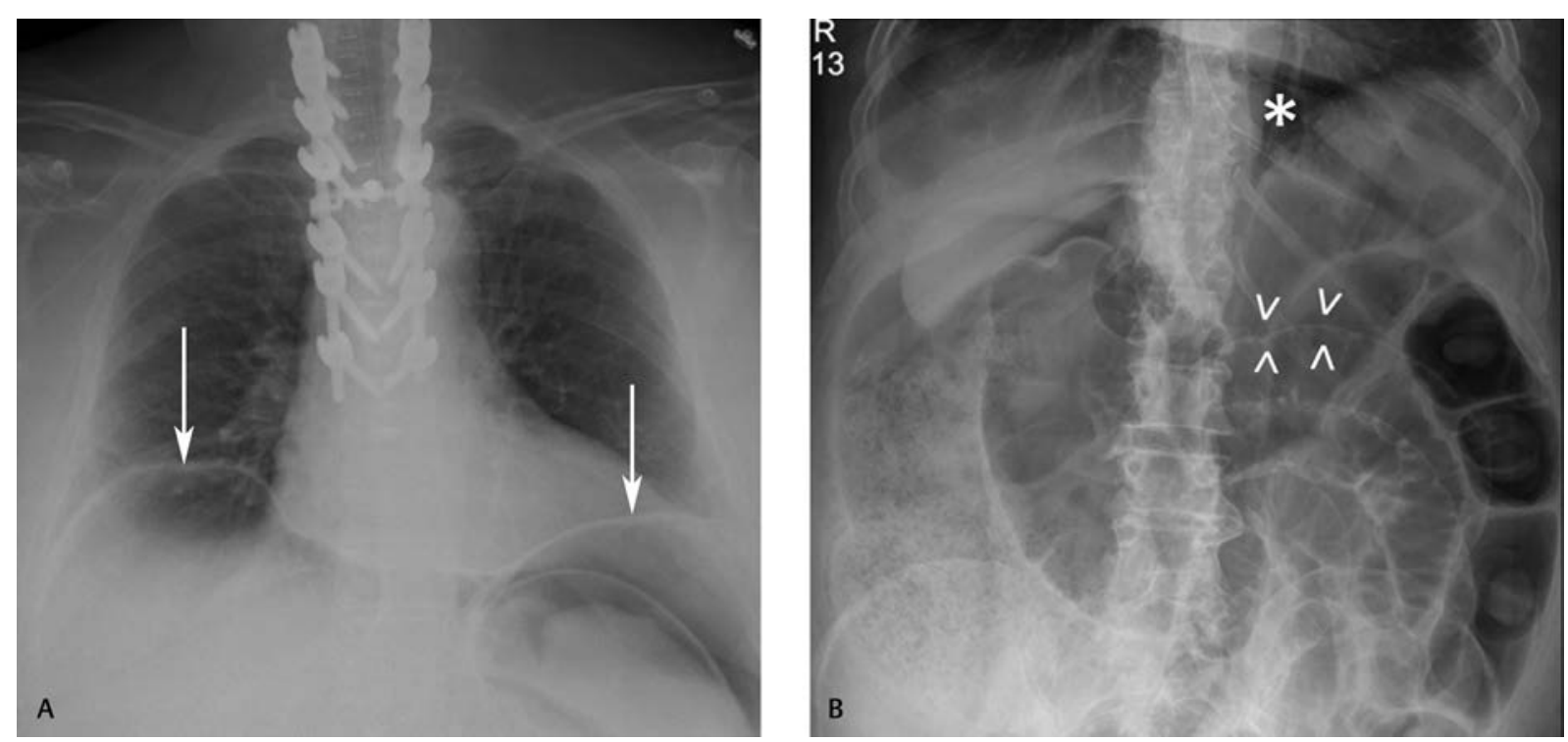

Fig. 1 Pneumoperitoneum. A 53-year-old woman who underwent neurosurgical decompression with fusion of multiple cervical and thoracic vertebrae and developed diffuse colonic distension over the next 5 days, consistent with Ogilvie syndrome. She subsequently developed right colonic perforation. Large amount of free air is seen under bilateral hemidiaphragms on frontal chest radiograph (arrows in $\mathbf{A}$ ). Supine anteroposterior radiograph of the abdomen (B) demonstrates Cupola sign (asterisk) and double wall sign (arrowheads).
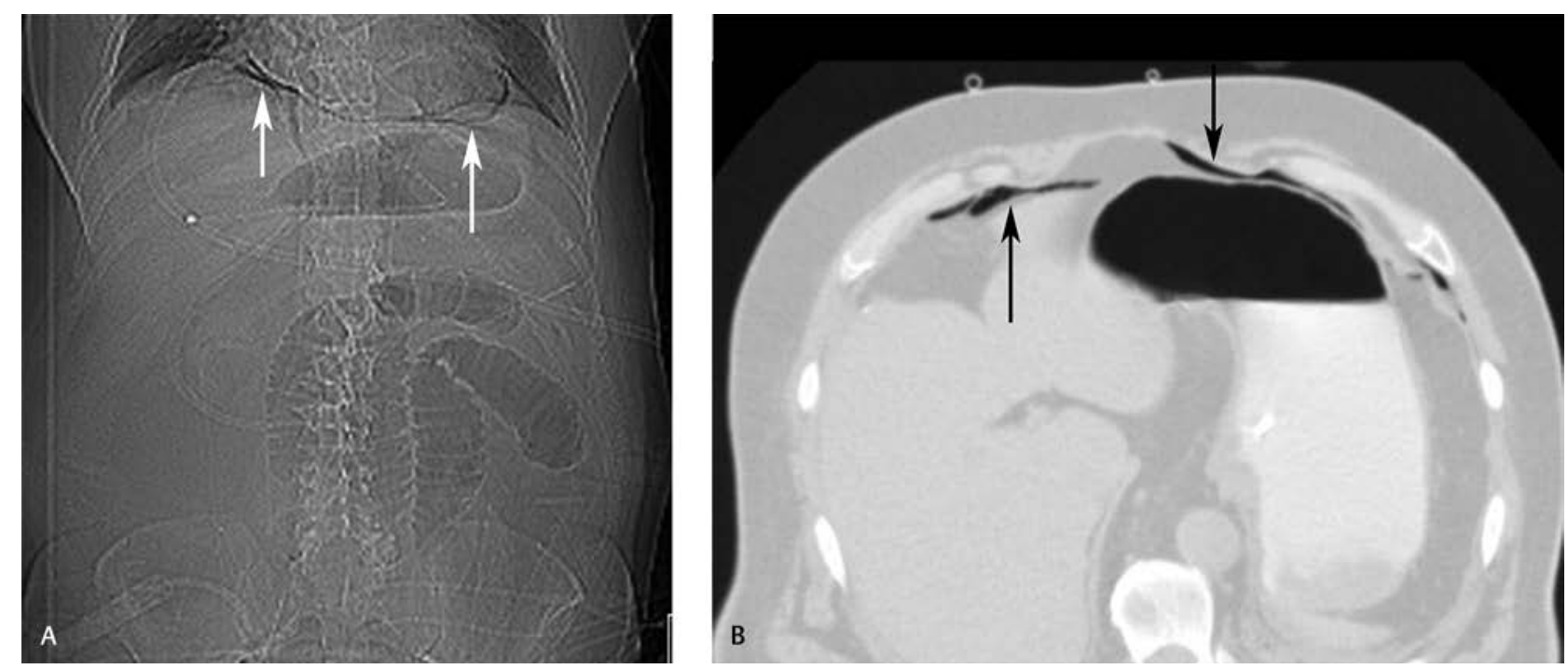

Fig. 2 Extraperitoneal air. A 44-year-old man with a history of barotrauma. Computed tomography (CT) scout of the abdomen (A) showing dissection of air into extraperitoneal soft tissue of anterior abdomen. Axial CT in lung windows (B) shows linear air collections (arrow); presence of thin muscular/vascular septations is the key to diagnosing extraperitoneal air.

Table 1 Causes of pneumoperitoneum

\begin{tabular}{|l|}
\hline $\begin{array}{l}\text { 1. Perforated hollow viscus-trauma, infection, tumor, } \\
\text { ischemia, obstruction }\end{array}$ \\
\hline 2. Volvulus \\
\hline 3. Hernia \\
\hline 4. Postprocedural-endoscopy, ERCP, surgery \\
\hline $\begin{array}{l}\text { 5. Extension from pneumomediastinum, } \\
\text { pneumoretroperitoneum }\end{array}$ \\
\hline
\end{tabular}

Abbreviation: ERCP, endoscopic retrograde cholangiopancreatography.

\section{Pneumobilia}

Pneumobilia is accumulation of air in the biliary tree. Common causes of pneumobilia include postinstrumentation (ERCP), sphincter of Oddi dysfunction ( - Fig. 4) (which can be iatrogenic postsphincterotomy), and surgical or spontaneous biliary-enteric fistulas (commonly secondary to peptic ulcer disease). ${ }^{17}$ Passage of a gallstone, gallstone ileus (identifiable by the Rigler triad on plain abdominal films: pneumobilia, small bowel obstruction, and an ectopic gallstone), ${ }^{18}$ infection, and trauma are other conditions leading to pneumobilia. 

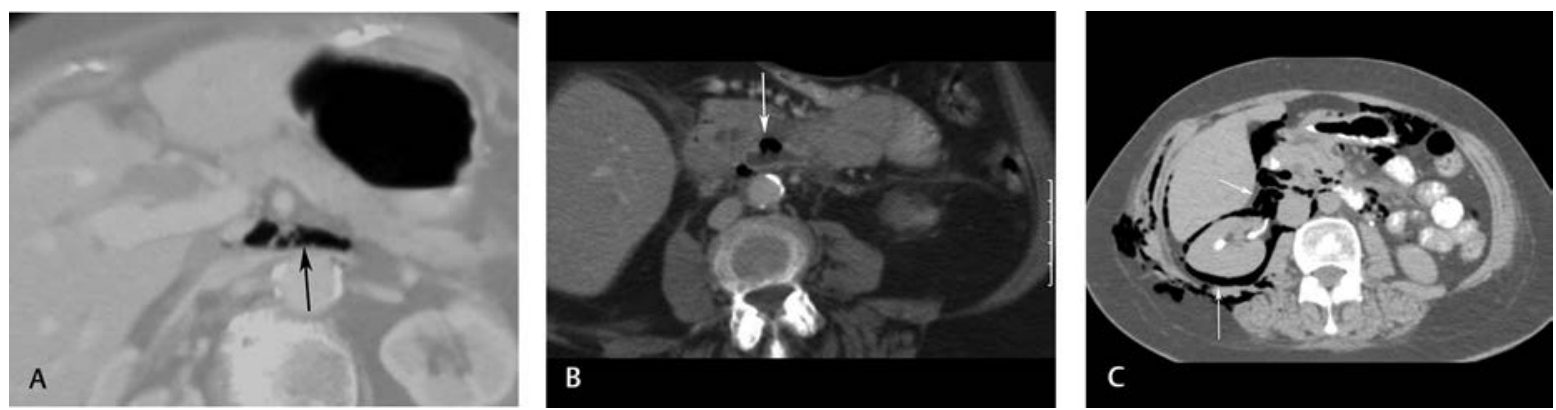

Fig. 3 Pneumoretroperitoneum. A 44-year-old man presented to the emergency room with acute abdominal pain. Axial computed tomography (CT) images in portal venous phase showing presence of retroperitoneal free air (arrow) anterior to the abdominal aorta (A). Inflammatory stranding with free air is seen around third part of duodenum (arrow) suggesting a perforation of a duodenal ulcer (B), which was confirmed per-operatively. (C) A 39-year-old woman with a history of sclerosing cholangitis, status post common bile duct stent placement 2 days ago. Axial postcontrast CT abdomen in excretory phase demonstrates free air in the retroperitoneum adjacent to the 2nd and 3rd portions of the duodenum, surrounding the inferior vena cava, in the anterior and posterior pararenal spaces (arrows), and within the lateral abdominal wall.

Table 2 Causes of pneumoretroperitoneum

\begin{tabular}{|l|}
\hline 1. Perforated hollow viscus-trauma, infection, tumor \\
\hline 2. Emphysematous cholecystitis \\
\hline $\begin{array}{l}\text { 3. Postsurgical-hemorrhoidectomy, transanal excision of } \\
\text { tumor, spinal surgery }\end{array}$ \\
\hline 4. Postprocedural-ERCP with sphincterotomy, colonoscopy \\
\hline
\end{tabular}

Abbreviation: ERCP, endoscopic retrograde cholangiopancreatography.

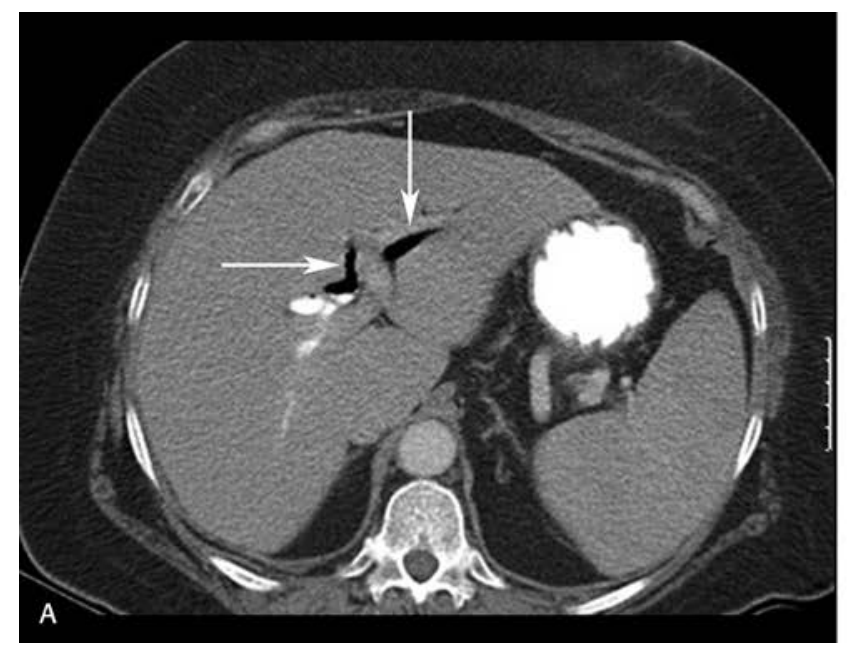

\section{Portal Venous Air}

Portal venous gas (-Fig. 6) can arise from untreated cholecystitis as mentioned, or from a similar mechanism when gas producing organisms in the gastric wall (emphysematous gastritis) lead to intraluminal air dissection into the stomach wall and duodenum with absorption into the portal venous system. This can be secondary to bowel ischemia, inflammatory bowel disease, immunosuppression, or other causes. ${ }^{20}$ Emphysematous gastritis is shown in - Fig. 6.

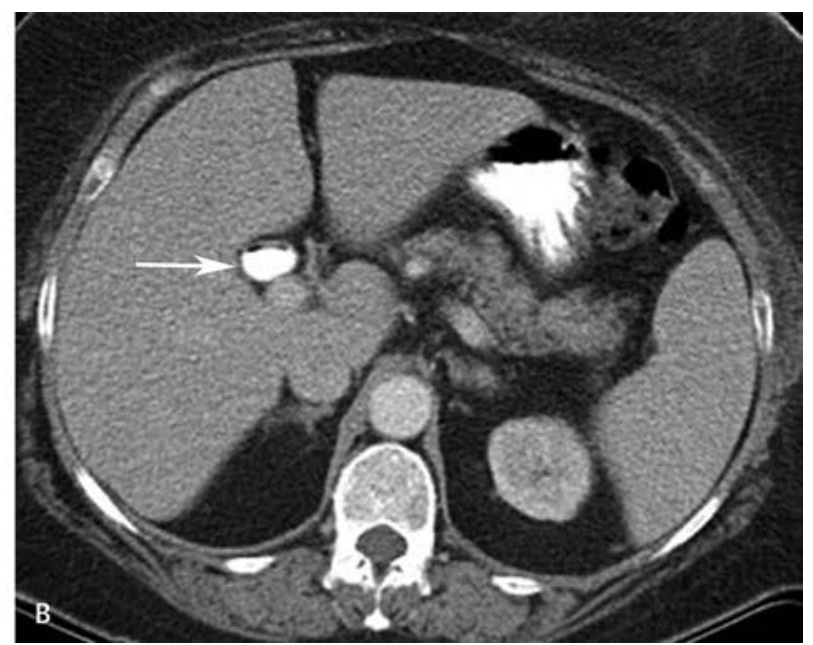

Fig. 4 Pneumobilia. A 53-year-old female with choledochojejunostomy. Axial computed tomography in portal venous phase shows pneumobilia (arrows in A) which was secondary to reflux from air in the jejunum. Radio-opaque contrast is also seen in the biliary tree (arrow in $\mathbf{B}$ ).

Gas in the gallbladder is seen in emphysematous cholecystitis (-Fig. 5), a form of acute cholecystitis. It is a surgical emergency and must be distinguished from portal venous gas (which may also be an emergent finding depending on the underlying pathology). Seen on plain radiography, there is a relatively central location of linear air density in the liver in pneumobilia in comparison to peripheral linear air densities as seen with portal venous gas. Computed tomography (CT) is the definitive imaging modality and is the most sensitive and specific for detecting air in the gallbladder. Emphysematous cholecystitis must be promptly diagnosed by the radiologist as the air present can dissect into portal veins secondary to ischemia of gallbladder wall. ${ }^{19}$

\section{Intraparenchymal Air}

Air visualized within hepatic parenchyma is commonly the result of liver abscesses caused by gas-forming bacteria. On CT, small pyogenic abscesses can demonstrate a "cluster sign" wherein the abscesses appear to cluster, or aggregate, in a pattern that suggests coalescence into a single, larger abscess cavity. This is a pattern which is not found in abscesses arising from mycobacterial or fungal etiologies. ${ }^{21}$ Parenchymal gas can also be seen following instrumentation or interventional procedures and is a common transient finding on US following orthotopic liver transplant. These patients must be evaluated carefully; however, as hepatic artery thrombosis is a potentially 

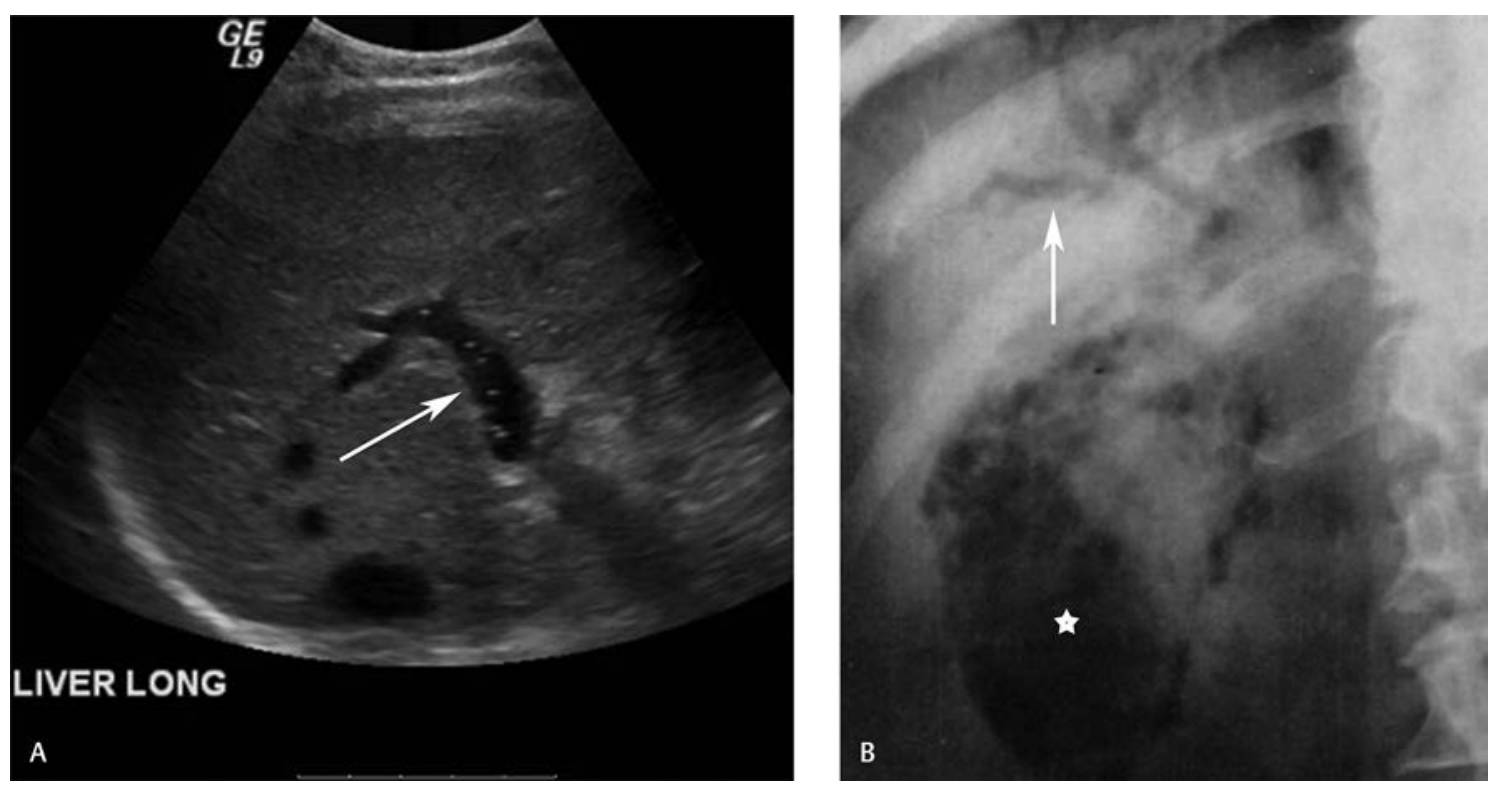

Fig. 5 Emphysematous cholecystitis. A 64-year-old diabetic man with acute emphysematous cholecystitis secondary to acalculous cholecystitis due to clostridium infection. Sonographic image through the liver (A) showing reverberation artifacts in the biliary tree (arrow). Plain radiograph of the abdomen $(\mathbf{B})$ revealed mottled lucencies in the region of the gall bladder (asterisk) and biliary tree (arrow).
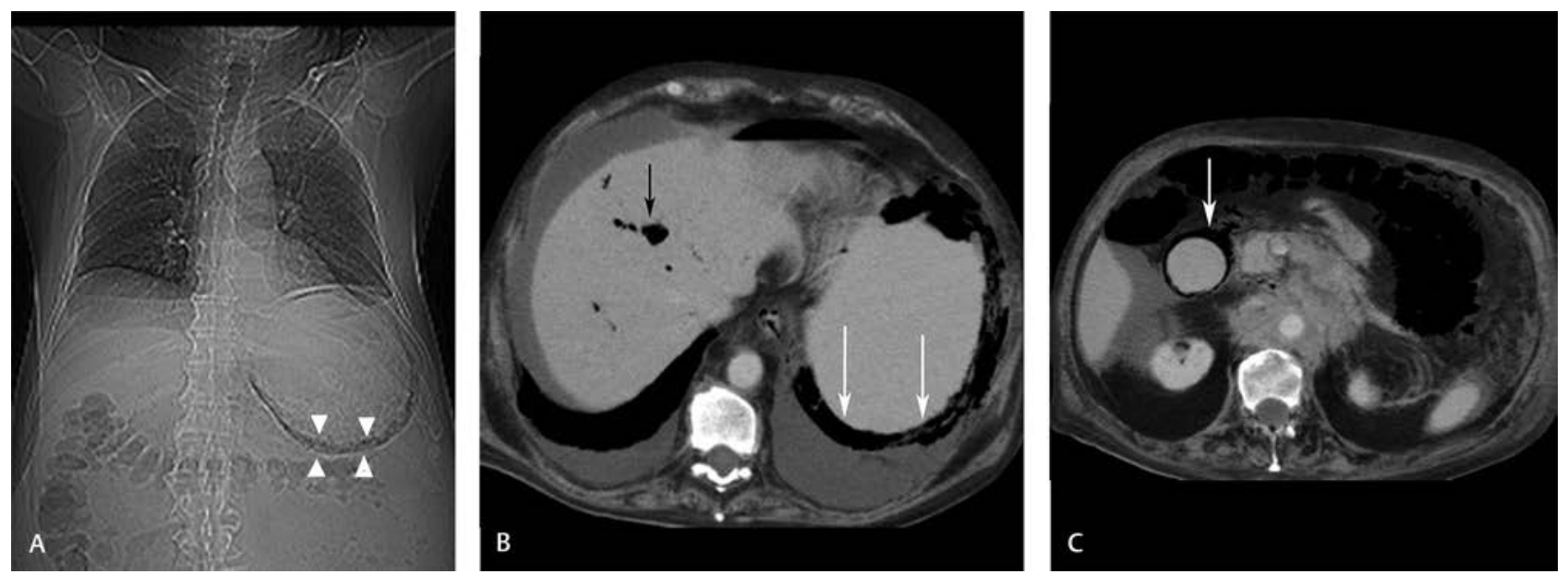

Fig. 6 Emphysematous gastritis and portal venous air. A 55-year-old man with lymphoma and neutropenia having emphysematous gastritis secondary to enterococcal infection. Computed tomography (CT) scout of the abdomen (A) showing intraluminal air dissection into the stomach (arrowheads). Axial CT sections (B and $\mathbf{C}$ ) through the abdomen in portal venous phase showing air in stomach and duodenal wall (arrows) with absorption into portal venous system (black arrow in B).

severe complication of liver transplant which can lead to gas gangrene of the graft. ${ }^{22}$

Emphysematous hepatitis is a rare and fatal condition distinguishable from typical pyogenic liver abscesses. This condition is characterized by widespread replacement of hepatic parenchyma with gas without the presence of discrete abscesses. The pathogenesis remains unclear, although there appears to be association with diabetes and other immunocompromised states. There are currently no treatment guidelines for this fulminant condition as adequate surgical debridement is generally unobtainable and attempts at percutaneous drainage and antibiotics have not been reported to be effective. ${ }^{23,24}$

Emphysematous pancreatitis is a rare and life-threatening condition associated with acute pancreatitis. Plain radiography typically shows nonspecific findings, such as scattered gas in the mid abdomen. CT is the modality of choice for recognizing the presence of retroperitoneal free air within pancreatic parenchyma and/or the lesser sac (-Fig. 7). The infection is most commonly polymicrobial involving gas-forming organisms including anaerobes and gram-negative bacteria (e.g., Escherichia coli, Clostridium, Staphylococcus, Streptococcus, Klebsiella, Candida, and Pseudomonas). ${ }^{25}$ Other common sources of pancreatic air include enteric fistulas, reflux from the small bowel following sphincterotomy or endoscopic instrumentation, and uncomplicated tissue infarction. ${ }^{26}$

Air within the spleen is rare and has historically been visualized primarily in the setting of typical pyogenic abscesses or fistulous communication with adjacent gas-filled organs. 


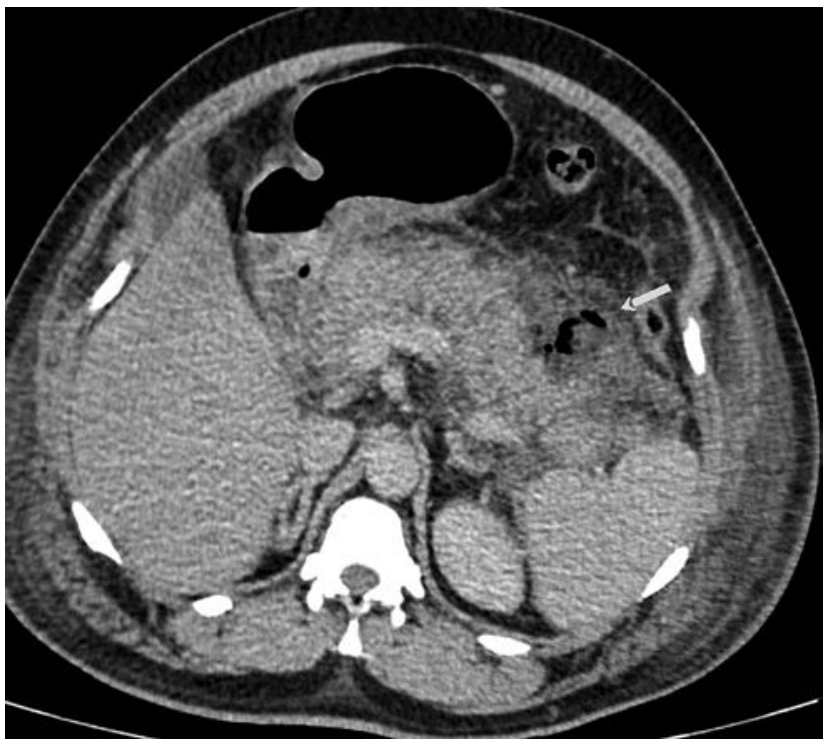

Fig. 7 Emphysematous pancreatitis. A 40-year-old man with a history of chronic alcoholism presented with acute abdominal pain radiating to the back. Axial computed tomography in portal-venous phase demonstrates changes of acute pancreatitis with a pocket of air overlying the distal body/tail region (arrow). Image courtesy: Dr. Rochita V. Ramanan.

However, as the use of splenic embolization for nonoperative management has become more common, findings of air within the infarcted areas have increased as well (-Fig. 8). The etiology of this air is unknown; however, Haan et al evaluated a cohort of these patients and found that in the absence of clinical symptoms it is unlikely to be infectious in origin. ${ }^{27}$

Pneumatosis intestinalis is presence of gas in the bowel wall and is thought to be secondary to either mechanical infiltration of air from the bowel lumen, air from the mediastinum, penetration by gas forming bacteria, or a combination thereof. Benign causes are numerous and include

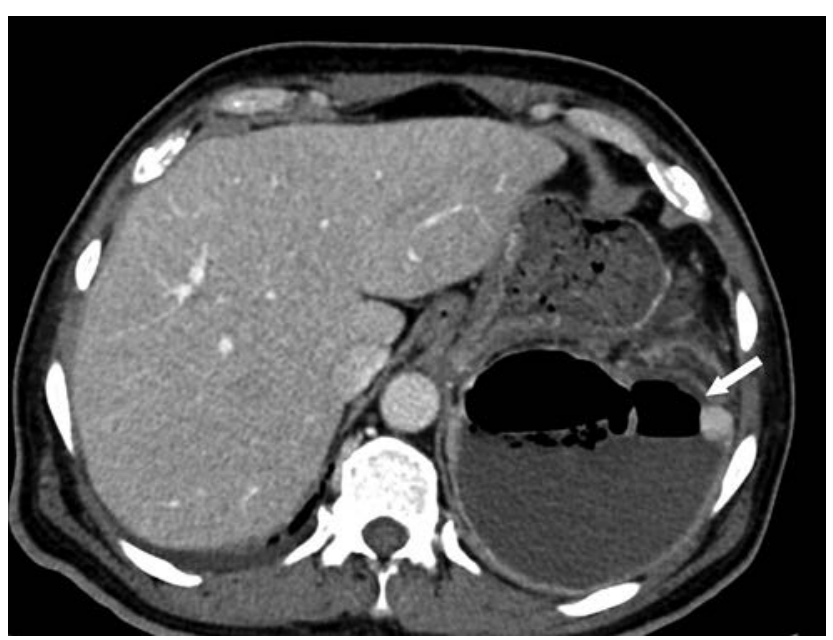

Fig. 8 Splenic abscess. A 38-year-old immunocompromised man with fever, chills, and rigors and left upper quadrant pain. Axial computed tomography in portal-venous phase demonstrates a large rim-enhancing fluid collection within the spleen with large amount of air within the collection (arrow). Image courtesy Dr. Rochita V. Ramanan. pulmonary (asthma, bronchitis, cystic fibrosis), gastric (enteritis, obstruction, inflammatory bowel disease), and iatrogenic (barium enema, endoscopy, surgical anastomosis) etiologies among others. Pneumatosis cystoides intestinalis is a benign variant that should be recognized. Importantly, findings on barium enema can resemble polyposis and it has been reported that removal of the "polyp" led to bowel perforation in some cases. ${ }^{28}$ Up to $15 \%$ of cases can be considered idiopathic and are usually located within the colon.

Pneumatosis intestinalis can also be the hallmark potentially fatal conditions such as intestinal ischemia (Fig 9), toxic megacolon, necrotizing enterocolitis in neonates, or trauma. ${ }^{29,30}$

The patterns of the radiolucencies are seen as linear, circular, or as small bubbles. Pneumatosis cystoides ( - Fig. 9) is the most common presentation of pneumatosis. A subtle but highly specific finding of bowel ischemia is nonenhancement of the bowel wall on contrast-enhanced CT. Ideally, such studies should be performed without oral contrast to appreciate this finding. ${ }^{31}$

Air in the kidneys and upper urinary tract is most commonly due to infection. Other causes can be iatrogenic, fistulas, reflux from the bladder, or the result of trauma. Emphysematous pyelonephritis ( - Fig. 10) is a rare but severe infection primarily found in diabetics with poor glucose control but has also been described in cases of nephrolithiasis ${ }^{32}$ and tumors. It is characterized by presence of intraparenchymal, intracalyceal, and intrapelvic gas and extension into the perinephric space. The most common causative organism is Escherichia coli, followed by Klebsiella and Proteus. On CT, emphysematous pyelonephritis is classified into two types: type 1 is more aggressive and shows streaky or mottled areas of gas representing parenchymal destruction seen extending radially along the pyramids, with no fluid collections. Type 2 shows bubbly or loculated areas of gas associated with renal and perirenal fluid collections, and/or demonstrates gas into the pelvicalyceal system or ureter. ${ }^{33}$

Emphysematous pyelitis is the presence of air only in the renal collecting system and/or ureter. Radiography shows gas outlining the ureter and dilated calices, with air-fluid levels which can sometimes be seen in the ureter. It is caused by the same organisms as emphysematous pyelonephritis but is more strongly associated with urolithiasis. Distinction between these two entities is important as emphysematous pyelitis carries a better prognosis and will respond to medical management, while emphysematous pyelonephritis requires intervention and drainage, if not complete nephrectomy. ${ }^{34}$

Frequently, the cause for an abnormal air collection in the abdomen or pelvis may lie in the chest which extends along fascial and subcutaneous planes and manifests itself in the abdomen. The most common cause is pneumomediastinum which is discussed below.

\section{Pneumomediastinum}

Trauma which results in perforation of air-containing organs of respiratory and gastrointestinal tracts is one of the most common reasons for developing pneumomediastinum 

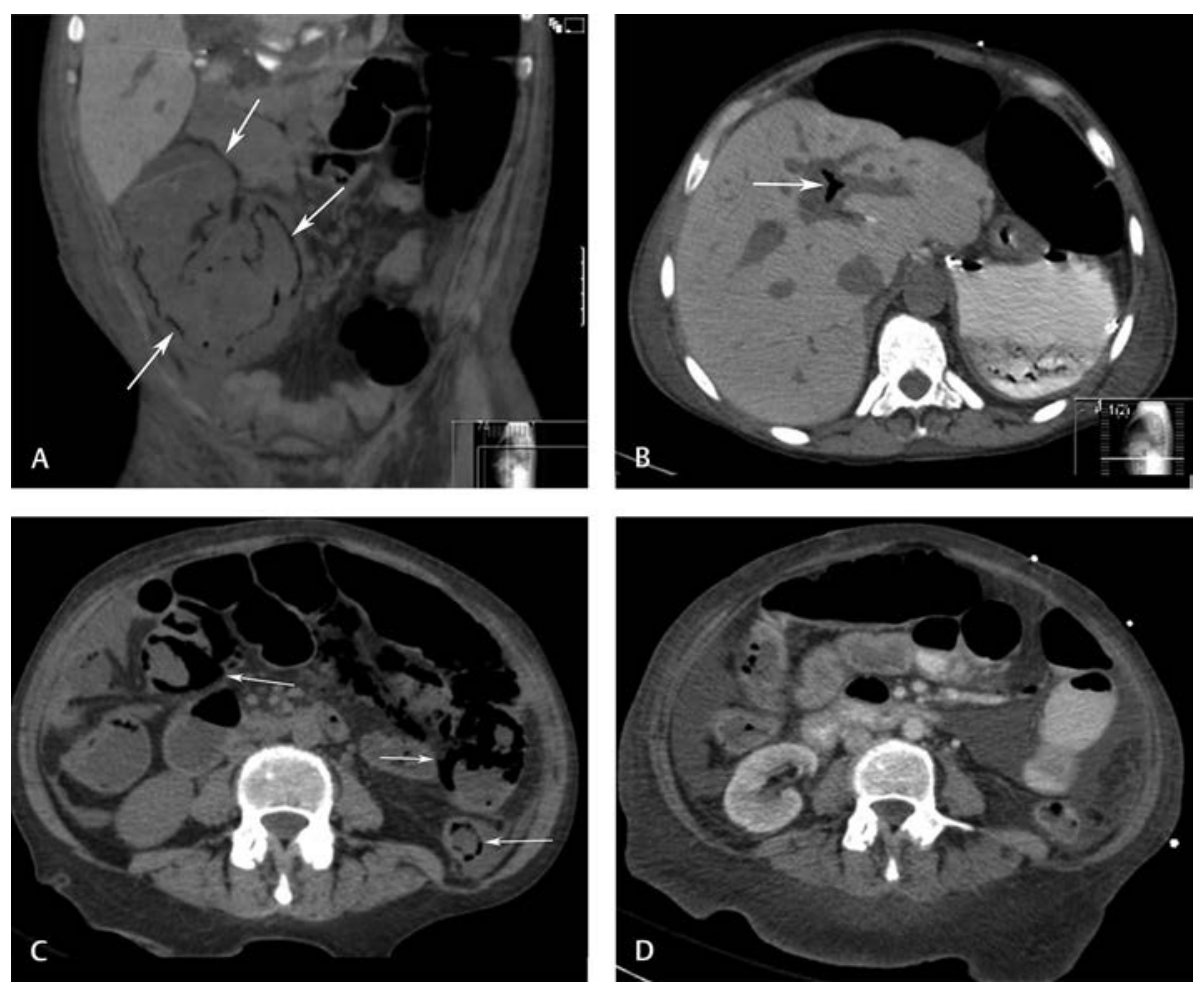

Fig. 9 Pneumatosis intestinalis. A 34-year-old man with sickle cell disease manifesting as ischemic colitis (arrow). Coronal reconstructed noncontrast computed tomography (CT) (A) image through the abdomen showing dissection of intraluminal air through ischemic bowel mucosa into the bowel wall. An axial CT section (B) showing absorption of air into portal venous system (arrow). Oral contrast is seen in the stomach. (C) Pneumatosis cystoides intestinalis. A 71-year-old woman status post recent total abdominal hysterectomy and bilateral salpingooophorectomy for endometrial cancer presenting with nausea and vomiting. Axial noncontrast CT demonstrates air in the bowel wall (arrows in C). (D) Follow-up contrasted CT in portal venous phase obtained after 48 hours demonstrates resolution of pneumatosis.
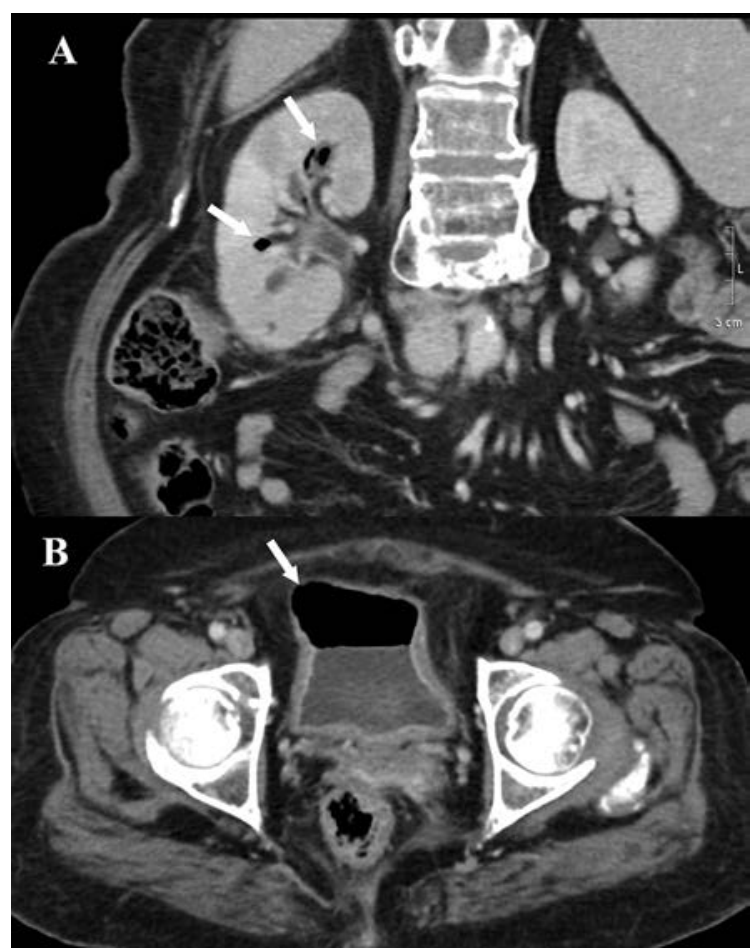

Fig. 10 Emphysematous pyelonephritis. A 60-year-old diabetic man presenting with fever and flank pain. Coronal (A) and axial (B) portal venous phase computed tomography images demonstrate air in the renal collecting system (arrows in $\mathbf{A}$ ) with patch parenchymal hypodensities, consistent with emphysematous pyelonephritis. Air is also visualized in the lumen of the urinary bladder (arrow in B). Images courtesy: Dr. Rochita V. Ramanan.
(-Fig. 11). In hospitalized patients, tracheoesophageal fistula due to overinflated endotracheal tube cuff ( - Fig. 12), leading to pressure necrosis of tracheal and esophageal wall, can eventually be associated with pneumomediastinum. ${ }^{35}$

As with pneumothorax, pneumomediastinum can also occur spontaneously in patients with asthma or croup. The pathophysiology of pneumomediastinum in these cases is the emergence of a pressure gradient between the alveoli and the surrounding structures that, upon reaching a critical level, causes alveolar rupture with air leak into the interstitium, causing interstitial emphysema. The air dissects along the bronchovascular bundle towards the mediastinum which is the path of least resistance owing to lower pressure. Due to contiguity of fascial planes, it can reach the subcutaneous tissue and the peritoneum. Increased pressure within the mediastinum leads to rupture of mediastinal pleura, causing pneumothorax. ${ }^{36,37}$

Increased intrathoracic pressure such as from vigorous exercise, child birth, violent retching, mechanical ventilation, thoracic trauma including rib fracture, bronchotracheal laceration are other causes of pneumomediastinum (-Fig. 13). Rarely, extension of mediastinal air may be seen into the spinal epidural space producing pneumorrhachis (-Fig. 13C).

Esophageal injury from instrumentation and vomiting (-Fig. 14) and airway injury from difficult intubation have also been reported to be associated with pneumomediastinum. ${ }^{38}$

Invasive procedures such as thoracotomy or mediastinoscopy can also have postprocedure pneumomediastinum. 

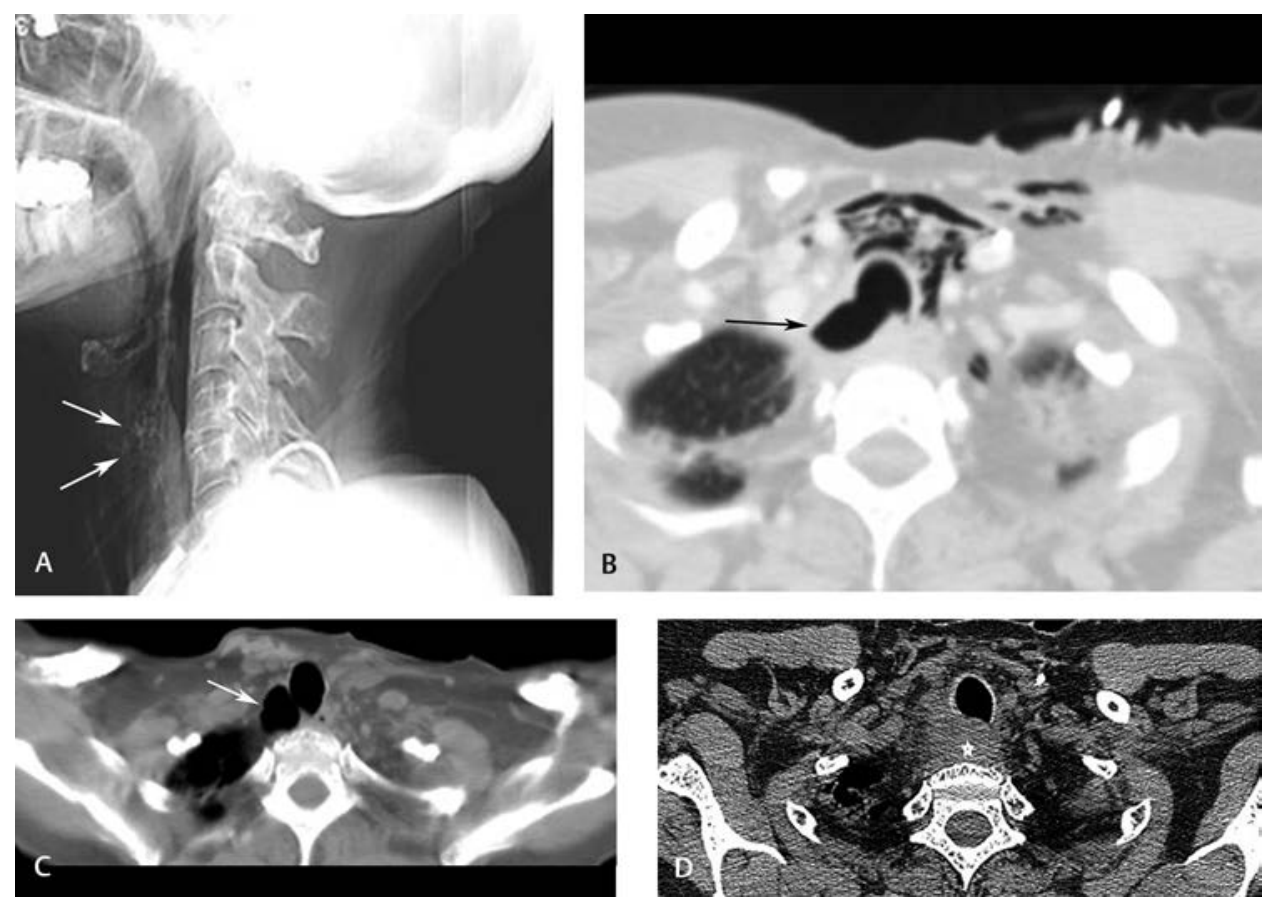

Fig. 11 Pneumomediastinum. A 62-year-old man with multiple myeloma expectorated fungal ball from tracheal diverticulum leading to subcutaneous emphysema and pneumomediastinum. Lateral plain radiograph of the neck (A) shows presence of free air in anterior soft tissues of the neck (arrows). Axial postcontrast computed tomography (CT) (B) images through the upper chest in lung windows reveal tracheal diverticulum (arrow) arising from posterolateral tracheal wall with associated subcutaneous emphysema and pneumomediastinum. Patchy areas of fibrosis are noted in bilateral lungs. Axial postcontrast CT images (C) obtained few days earlier reveled unruptured tracheal diverticulum (arrow). Another axial noncontrast CT (D) image obtained at a different time shows abnormal density occupying the tracheal diverticulum, confirmed to be an aspergillus fungal ball (asterisk).
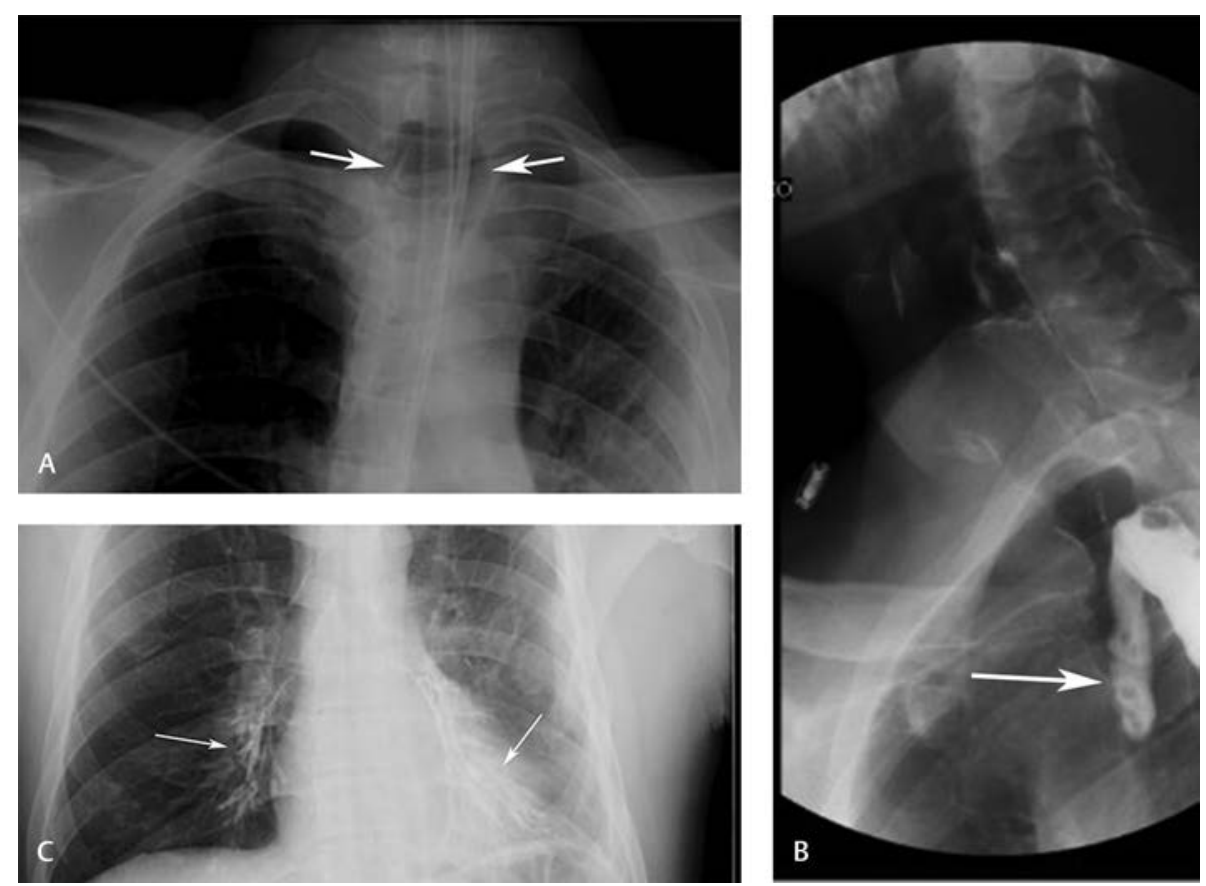

Fig. 12 Pneumomediastinum. A 43-year-old man developed tracheoesophageal fistula as a complication of overinflated endotracheal tube cuff. Frontal plain radiograph of the chest (A) shows overinflated cuff of the endotracheal tube (arrows). Gastrografin esophagogram revealed leakage of contrast (arrow) into the tracheal lumen (B) and lining of bronchial tree (C) by contrast media (arrows).

Mediastinal air can dissect into the pleural space to produce pneumothorax. It can also can track into the neck, and lead to pneumopericardium through air tracking along the pulmonary veins. ${ }^{2}$
Various radiological signs for pneumomediastinum have been described in literature. These are based on outlining of anatomical structures by air that has escaped from the mediastinum. Elevation of thymus by air produces the 

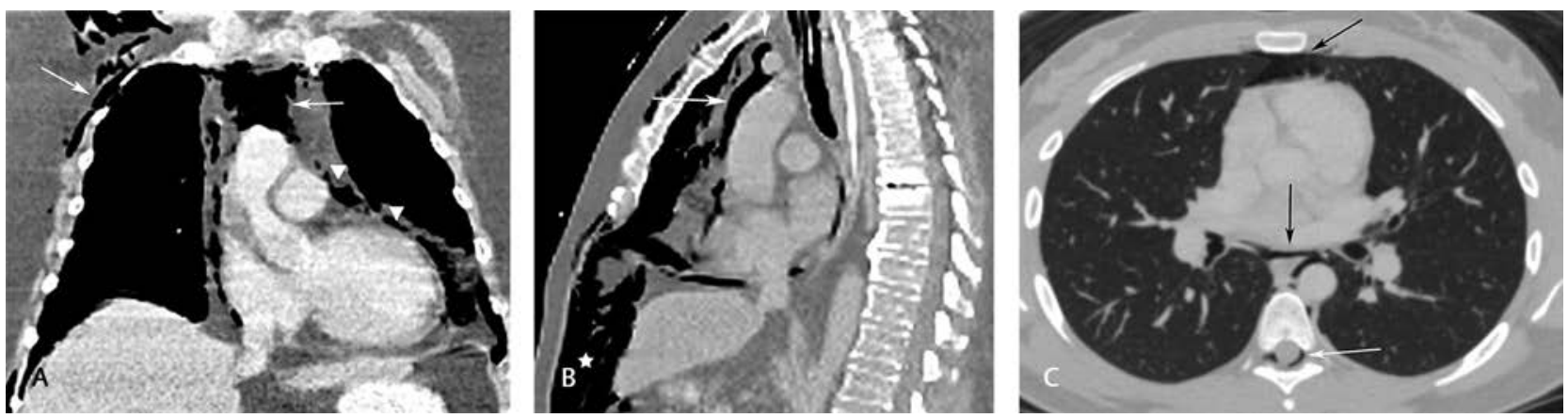

Fig. 13 Pneumomediastinum and pneumorrhachis secondary to barotrauma. Coronal and sagittal postcontrast chest computed tomography (CT) images of a 70-year-old intubated man with pneumomediastinum (short white arrows in $\mathbf{A}$ and $\mathbf{B}$ ), pneumopericardium (arrowheads in A), subcutaneous emphysema (long white arrow in A) and moderate pneumoperitoneum (asterisk in B) seen in the absence of any focal inflammatory changes, likely secondary to high ventilation pressure. Axial CT in lung windows demonstrates extension of mediastinal air into the spinal epidural space (white arrow in C).
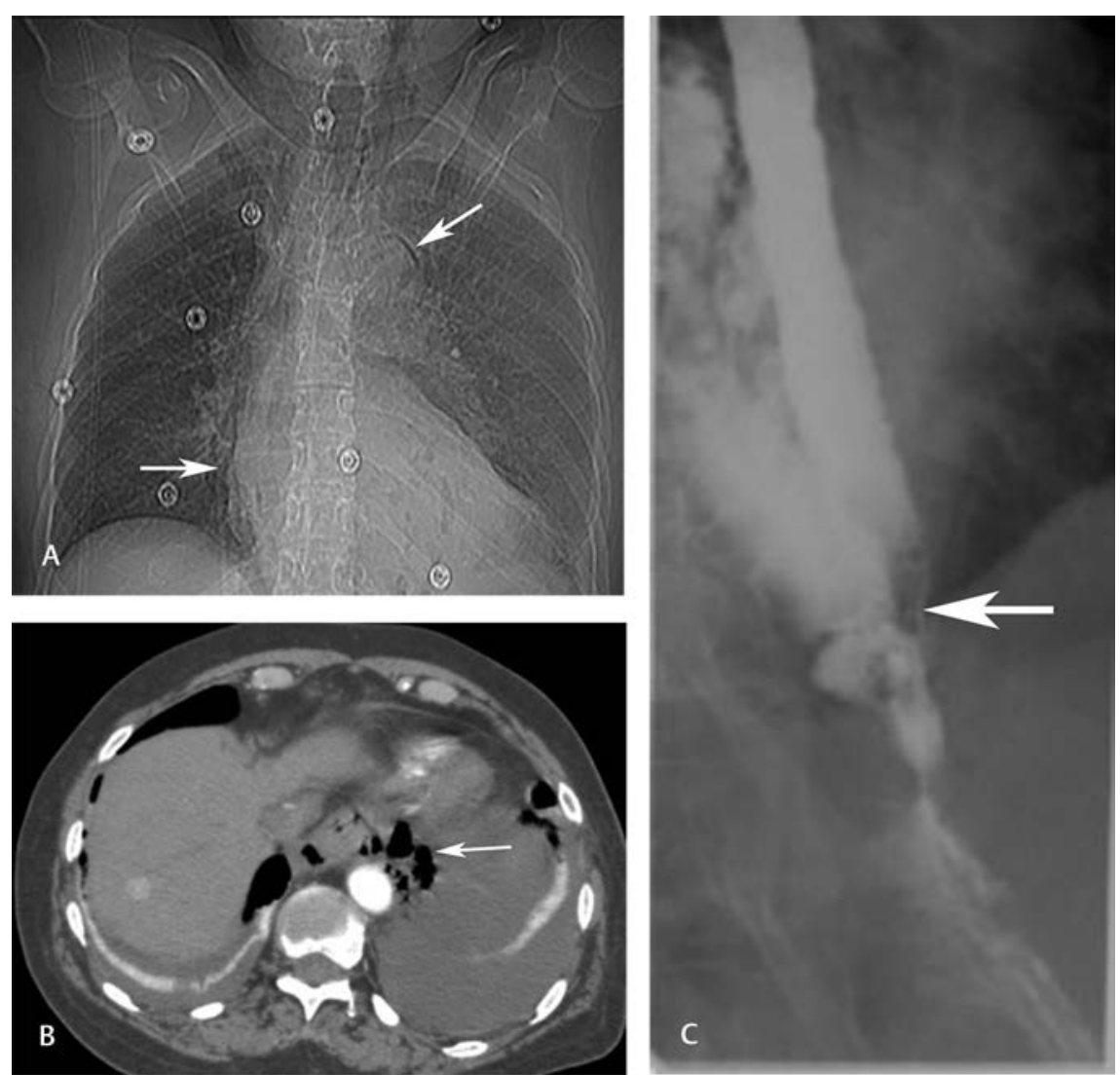

Fig. 14 Pneumomediastinum due to Boerhaave's syndrome. Computed tomography (CT) scout of the chest (A) of a 56-year old woman shows pneumomediastinum (arrows). Axial contrast-enhanced CT of the abdomen in arterial phase (B) reveals free air at the gastroesophageal junction (arrow). Gastrograffin swallow (C) in lateral projection shows extravasation of contrast (arrow) from lower esophagus from a longitudinal esophageal tear due to violent retching.

"thymic sail" sign. Air surrounding the pulmonary artery or its main branches can produce the "ring around the artery" sign. Air surrounding the major branches of aorta will cause both sides of the vessel to be depicted which is known as the "tubular artery" sign. Here, mediastinal air outlines the medial side and the aerated lung marginates the lateral side. Air residing next to the major bronchus can allow clear depiction of the bronchial wall and producing the "double bronchial wall" sign. Air trapping posterior to the pericardium can give the appearance of a continuous collection of air on frontal view, known as the "continuous diaphragm" sign. Air from the mediastinum can extend laterally between the parietal pleura and the diaphragm to produce the extrapleural sign. Air can also migrate from the mediastinum into the pulmonary ligament secondary to rupture of the distal esophagus. ${ }^{2}$ 

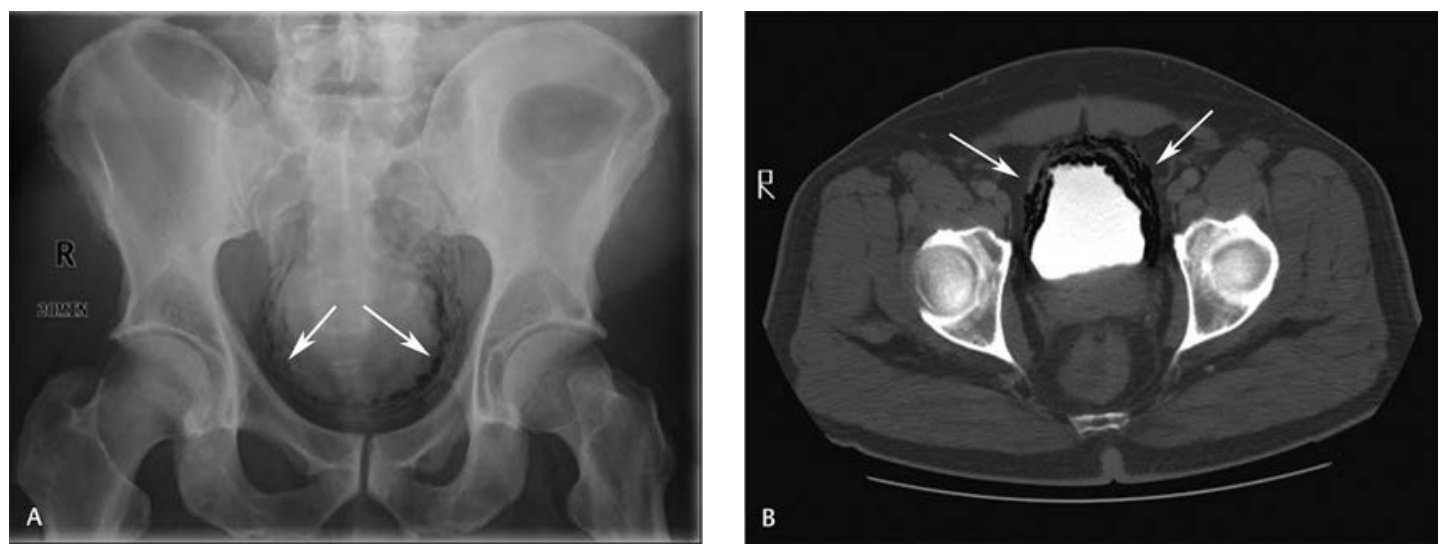

Fig. 15 Emphysematous cystitis. A 50-year-old diabetic man with Klebsiella urinary tract infection. Delayed intravenous pyelographic film (A) shows curvilinear lucencies surrounding the contrast filled bladder lumen (arrows). Axial noncontrast computed tomography (B) confirms the presence of air in the bladder wall, confirming the diagnosis of emphysematous cystitis.
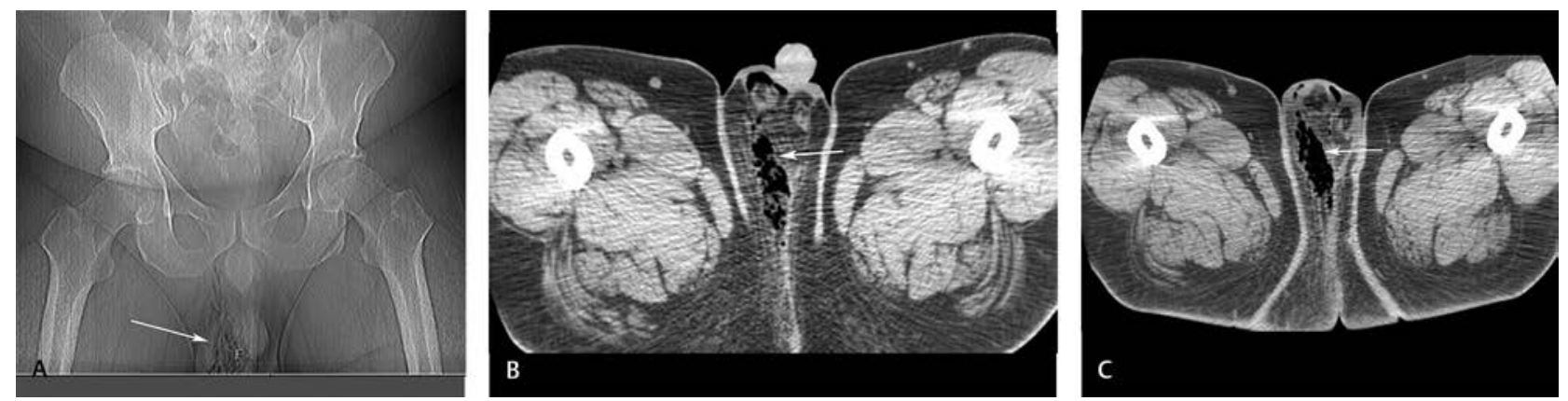

Fig. 16 Fournier's gangrene. A 50-year-old diabetic man with vague abdominal pain and septicemia. Scout radiograph of the pelvis (A) shows streaky linear lucencies overlying the scrotum (arrows). Axial portal venous phase computed tomography images of the pelvis (B and C) confirm presence of air in and around the right hemiscrotum (arrows) which are consistent with Fournier's gangrene.

\section{Imaging of Abnormal Air Collections in Pelvic} Organs

Abnormal air collections can accumulate in the pelvis within the bladder, pelvic organs such as uterus, and in the soft tissues. Infectious etiology is always higher up in the differential, particularly in the setting of uncontrolled diabetes and immunosuppression.

\section{Emphysematous Cystitis}

Emphysematous cystitis (-Fig. 15) is an inflammatory condition of the urinary bladder, commonly seen in elderly diabetic women, ${ }^{39}$ radiographically presenting as curvilinear areas of radiolucency within the bladder wall. Intraluminal air in the bladder can be seen in the presence of colovesical fistula, which can arise as a complication of diverticulitis, invasion from an adjoining malignancy, or abdominal surgery, among other etiologies. ${ }^{40}$

Air seen within the uterus is most commonly a result of infectious or neoplastic processes. Uterine abscesses may develop during the postpartum period. Gas gangrene of the uterus is a rare manifestation of primary uterine infection by Clostridium species occurring after septic abortion. ${ }^{41}$ Air found within the uterine wall is most commonly a result of an underlying neoplasm and necrosis. Fistula formation related to uterine leiomyoma, endometrial or cervical carcinoma, and colon carcinoma are possibilities as well. More benign etiologies of uterine air that must be excluded include non-neoplastic fistula formation with the bowel, recent instrumentation, and sexual intercourse. ${ }^{42}$

\section{Pneumoscrotum}

Pneumoscrotum is subcutaneous collection of air in the scrotum. It can be seen secondary to infection related to Fournier's gangrene (-Fig. 16), ${ }^{43}$ urethral injury, extension of pneumoperitoneum, ${ }^{44}$ scrotal trauma, and visceral perforations. It may also occur from a variety of iatrogenic causes such as colonoscopy and surgical procedures of the abdomen. ${ }^{45}$

\section{Necrotizing Fasciitis}

Necrotizing fasciitis is characterized by gas dissecting through fascial planes in the absence of history of penetrating trauma (-Fig. 17). While the presence of gas in soft tissues is specific for necrotizing fasciitis, it is not a sensitive finding. Absence of significant vascular occlusion and absence of Clostridia from tissue culture both of which are findings associated with gas gangrene are not usually associated with necrotizing fasciitis. Gas in muscles is nonspecific and can be seen with many soft tissue infections and is not characteristic of gas gangrene. Since rapid destruction of tissues is expected in Fournier's gangrene, early surgical debridement is always performed. Staphylococcus aureus and methicillin-resistant Staphylococcus aureus are the most commonly isolated organisms isolated from abscesses. $^{46}$ 


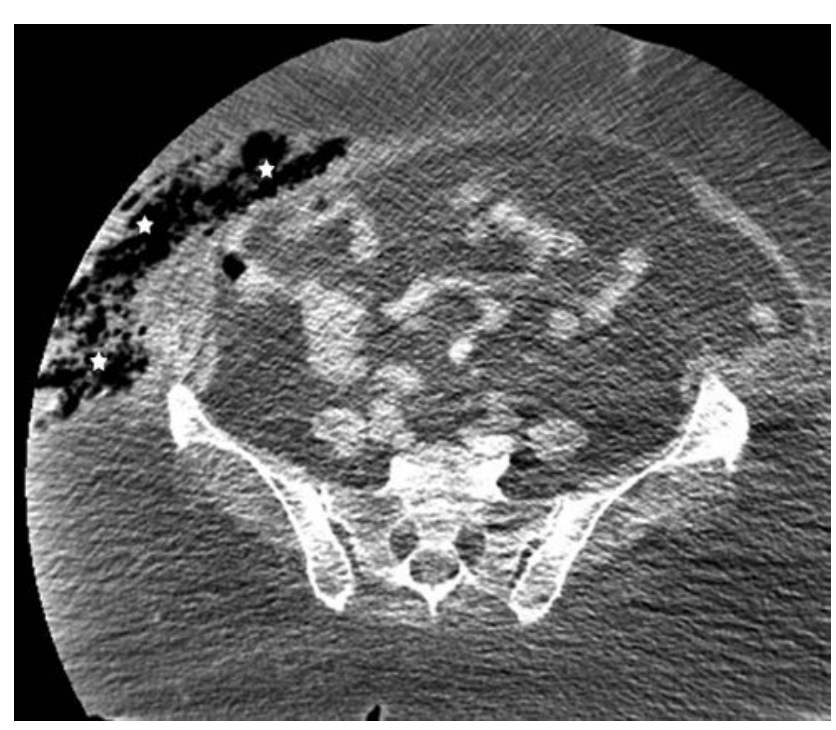

Fig. 17 Necrotizing fasciitis. A 40-year-old morbidly obese woman with uncontrolled diabetes admitted in the intensive care unit with sepsis. Axial portal venous phase computed tomography demonstrates extensive necrotizing fasciitis involving the abdominal wall (asterisks). Unfortunately, the patient succumbed due to systemic complications of necrotizing fasciitis. within the joint capsule on plain films or CT. Associated abscesses may also be seen. ${ }^{47}$

\section{Conclusion}

Presence of air is an important diagnostic clue to various disease pathologies. When a collection of air is encountered, one should aim at localizing the abnormal air as to determine the source and obtain detailed clinical information, both of which are equally crucial for radiological assessment. In many clinical scenarios, presence of air in an abnormal location is iatrogenic or expected after trauma, and follow-up imaging may demonstrate resolution or significant interval improvement. However, in certain situations it may be an ominous sign of a serious infection or hollow viscus injury and warrants immediate attention and intervention. This is particularly true for air collections encountered in the abdominal and pelvic organs. Interpretation of imaging characteristics and underlying pathological mechanisms of abnormal air collections is the key to developing and narrowing the differential diagnosis.
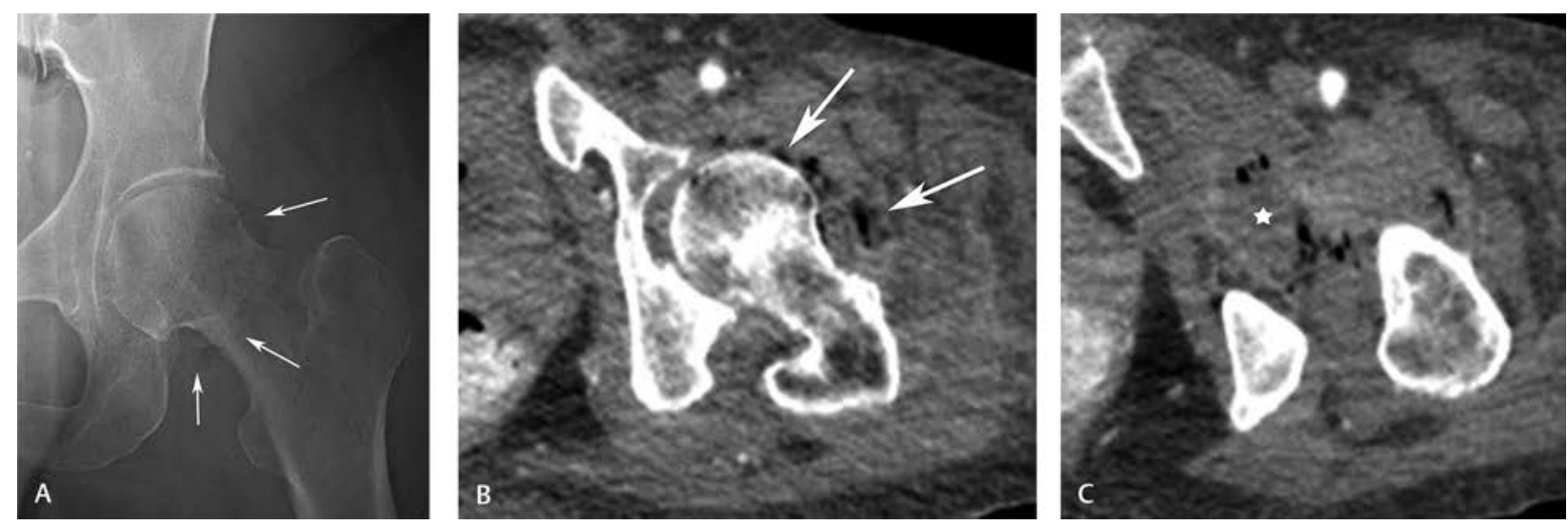

Fig. 18 Septic arthritis. A 65-year-old man presenting with left hip pain. Anteroposterior radiograph of the left hip (A) and axial computed tomography angiography (B and $\mathbf{C}$ ) at the level of the left hip demonstrate locules of air within the left hip joint (arrows). An abscess (asterisk) is seen caudally $(\mathbf{C})$.

\section{Septic Arthritis}

Septic arthritis resulting from gas-forming organisms is uncommon. It can be caused by direct inoculation of the joint from surgery, percutaneous procedure, or trauma. A native joint may develop septic arthritis ( - Fig. 18) secondary to hematogenous spread in patients with bacteremia or infectious endocarditis. Immunosuppression and dialysis are additional predisposing factors for developing septic arthritis. Clostridium species is the commonest anaerobic organism associated with septic arthritis. The infection may frequently be polymicrobial. Septic arthritis from gasforming organisms (Clostridium) can manifest as air seen

\section{Conflict of Interest}

None declared.

\section{References}

1 Kleinman PK, Brill PW, Whalen JP. Anterior pathway for transdiaphragmatic extension of pneumomediastinum. Am J Roentgenol 1978;131(2):271-275

2 Zylak CM, Standen JR, Barnes GR, Zylak CJ. Pneumomediastinum revisited. Radiographics 2000;20(4):1043-1057

3 Calenoff L, Poticha SM. Combined occurrence of retropneumoperitoneum and pneumoperitoneum. Am J Roentgenol Radium Ther Nucl Med 1973;117(2):366-372 
4 Frias Vilaça A, Reis AM, Vidal IM. The anatomical compartments and their connections as demonstrated by ectopic air. Insights Imaging 2013;4(6):759-772

5 Christensen EE, Landay MJ. Visible muscle of the diaphrag sign of extraperitoneal air. Am J Roentgenol 1980;135(3):521-523

6 Liao CY, Ben RJ, Ye YC, et al. Catastrophic pneumoperitoneum in a patient with perforated colorectal cancer with liver metastasis. Am J Emerg Med 2016;34(2):344.e3-344.e5

7 Singh JP, Steward MJ, Booth TC, Mukhtar H, Murray D. Evolution of imaging for abdominal perforation. Ann R Coll Surg Engl 2010;92(3):182-188

8 Antonopoulos P, Siaperas P, Troumboukis N, Demonakou M, Alexiou K, Economou N. A case of pneumoperitoneum and retropneumoperitoneum without bowel perforation due to extensive intestinal necrosis as a complication to chemotherapy: CT evaluation. Acta Radiol Short Rep 2013; 2(7):2047981613498723

9 Mularski RA, Sippel JM, Osborne ML. Pneumoperitoneum: a review of nonsurgical causes. Crit Care Med 2000;28(7):2638-2644

10 Chapman BC, McIntosh KE, Jones EL, Wells D, Stiegmann GV, Robinson TN. Postoperative pneumoperitoneu is it normal or pathologic? J Surg Res 2015;197(1):107-111

11 Rowe NM, Kahn FB, Acinapura AJ, Cunningham JN Jr. Nonsurgical pneumoperitoneu a case report and a review. Am Surg 1998;64(4):313-322

12 Fosi S, Giuricin V, Girardi V, et al. Subcutaneous emphysema, pneumomediastinum, pneumoretroperitoneum, and pneumoscrotu unusual complications of acute perforated diverticulitis. Case Rep Radiol 2014;2014:431563

13 Yagi Y, Sasaki S, Terada I, et al. Massive pneumoretroperitoneum arising from emphysematous cholecystitis: a case report and the literature review. BMC Gastroenterol 2015;15:114

14 Park YJ. Pneumoretroperitoneum after procedure for prolapsed hemorrhoid. Ann Coloproctol 2013;29(6):256-258

15 Araujo SE, Crawshaw B, Mendes CR, Delaney CP. Transanal total mesorectal excision: a systematic review of the experimental and clinical evidence. Tech Coloproctol 2015;19(2):69-82

16 Garcia P, Pizanis A, Massmann A, et al. Bilateral pneumothoraces, pneumomediastinum, pneumoperitoneum, pneumoretroperitoneum, and subcutaneous emphysema after thoracoscopic anterior fracture stabilization. Spine 2009;34(10):E371-E375

17 Sherman SC, Tran H. Pneumobilia: benign or life-threatening. J Emerg Med 2006;30(2):147-153

18 Dai XZ, Li GQ, Zhang F, Wang XH, Zhang CY. Gallstone ileus: case report and literature review. World J Gastroenterol 2013;19(33):5586-5589

19 Oyedeji FO, Voci S. Emphysematous cholecystitis. Ultrasound Q 2014;30(3):246-248

20 Abboud B, El Hachem J, Yazbeck T, Doumit C. Hepatic portal venous gas: physiopathology, etiology, prognosis and treatment. World J Gastroenterol 2009;15(29):3585-3590

21 Jeffrey RB Jr, Tolentino CS, Chang FC, Federle MP. CT of small pyogenic hepatic abscesses: the cluster sign. Am J Roentgenol 1988;151(3):487-489

22 Shah PA, Cunningham SC, Morgan TA, Daly BD. Hepatic gas: widening spectrum of causes detected at CT and US in the interventional era. Radiographics 2011;31(5):1403-1413

23 López Zárraga F, Aisa P, Saenz de Ormijana J, et al. Fulminant infection with emphysematous changes in the biliary tract and air-filled liver abscesses. Abdom Imaging 2006;31(1):90-93

24 Blachar A, Federle MP, Brancatelli G. Acute fulminant hepatic infection causing fatal "emphysematous hepatitis": case report. Abdom Imaging 2002;27(2):188-190

25 Wig JD, Kochhar R, Bharathy KG, et al. Emphysematous pancreatitis. JOP 2008;9(2):160-166
26 Kvinlaug K, Kriegler S, Moser M. Emphysematous pancreatitis: a less aggressive form of infected pancreatic necrosis? Pancreas $2009 ; 38(6): 667-671$

27 Haan J, Bochicchio G, Kramer M, Scalea T. Air following splenic embolization: infection or incidental finding? Am Surg 2003;69(12):1036-1039

28 Schröpfer E, Meyer T. Surgical aspects of pneumatosis cystoides intestinalis: two case reports. Cases J 2009;2:6452

29 Lee KS, Hwang S, Hurtado Rúa SM, Janjigian YY, Gollub MJ. Distinguishing benign and life-threatening pneumatosis intestinalis in patients with cancer by CT imaging features. Am J Roentgenol 2013;200(5):1042-1047

30 Kernagis LY, Levine MS, Jacobs JE. Pneumatosis intestinalis in patients with ischemia: correlation of CT findings with viability of the bowel. Am J Roentgenol 2003;180(3):733-736

31 Ho LM, Paulson EK, Thompson WM. Pneumatosis intestinalis in the adult: benign to life-threatening causes. Am J Roentgenol 2007;188(6):1604-1613

32 Gross IT, Ford R. Emphysematous pyelonephritis in a child with nephrolithiasis. J Pediatr 2016;168:250-e1

33 Craig WD, Wagner BJ, Travis MD. Pyelonephritis: radiologic-pathologic review. Radiographics 2008;28(1):255-277

34 Kua Ch, Abdul Aziz Y. Air in the kidney: between emphysematous pyelitis and pyelonephritis. Biomed Imaging Interv J 2008;4(4):e24

35 Bugge-Asperheim B, Birkeland S, Støren G. Tracheo-oesophageal fistula caused by cuffed tracheal tubes. Scand J Thorac Cardiovasc Surg 1981;15(3):315-319

36 Araujo MS, Fernandes FLA, Kay FU, Carvalho CR. Pneumomediastinum, subcutaneous emphysema, and pneumothorax after a pulmonary function testing in a patient with bleomycin-induced interstitial pneumonitis. J Bras Pneumol 2013;39(5):613-619

37 Khan WA, Abbas S, Bright J. Cervical and mediastinal emphysema associated with an asthma exacerbation. BMJ Case Rep 2013;2013:bcr2012008253

38 Banki F, Estrera AL, Harrison RG, et al. Pneumomediastinu etiology and a guide to diagnosis and treatment. Am J Surg 2013;206(6):1001-1006

39 Thomas AA, Lane BR, Thomas AZ, Remer EM, Campbell SC, Shoskes DA. Emphysematous cystitis: a review of 135 cases. BJU Int 2007;100(1):17-20

40 Golabek T, Szymanska A, Szopinski T, et al. Enterovesical fistulae: aetiology, imaging, and management. Gastroenterol Res Pract 2013;2013:617967

41 Joseph RC, Amendola MA, Artze ME, et al. Genitourinary tract gas: imaging evaluation. Radiographics 1996;16(2):295-308

42 Gross BH, Jafri SZ, Glazer GM. Significance of intrauterine gas demonstrated by computed tomography. J Comput Assist Tomogr 1983;7(5):842-845

43 Piedra T, Ruíz E, González FJ, Arnaiz J, Lastra P, López-Rasines G. Fournier's gangrene: a radiologic emergency. Abdom Imaging 2006;31(4):500-502

44 Patel C, Barnacle AM. Pneumoscrotum: a complication of pneumatosis intestinalis. Pediatr Radiol 2011;41(1):129

45 Cochetti G, Barillaro F, Cottini E, et al. Pneumoscrotu report of two different cases and review of the literature. Ther Clin Risk Manag 2015;11:581-587

46 Chaudhry AA, Baker KS, Gould ES, Gupta R. Necrotizing fasciitis and its mimics: what radiologists need to know. Am J Roentgenol 2015;204(1):128-139

47 Ho TT, Labriola L, Jouret F, et al. Clostridium perfringens hip arthritis in a haemodialysis patient. Acta Clin Belg 2012;67(1):49-50 